\title{
Techniques to Collect and Analyze the Cognitive Map Knowledge of Persons with Visual Impairment or Blindness: Issues of Validity
}

R.M. Kitchin, R.D. Jacobson

Abstract: This article is an assessment of a variety of techniques used by researchers in the fields of geography, psychology, urban planning, and cognitive science to collect and analyze data on how people with visual impairment or blindness learn, understand, and think about geographic space. The authors concluded that these techniques and their results need to be used cautiously. They also made recommendations for increasing the validity of future studies, including the use of multiple, mutually supportive tests; larger sample sizes, and movement from the laboratory to realworld environments.

Golledge (1993) suggested that the inability to travel independently and interact with the wider world is one of the most significant handicaps that can be caused by visual impairment or blindness, second only to the inability to communicate by reading and writing. Clark-Carter, Heyes, and Howarth (1986) reported that at least 30 percent of persons with visual impairment or blindness make no independent journeys outside their homes. The majority of those who do venture out adhere to known routes because exploration can lead to disorientation; chaos; and the fear,. stress, and panic associated with being lost (Golledge, 1993; Hill, et al., 1993). Such entrapment reduces the independence and 'quality of life for many persons with visual impairment or blindness. Cognitive mapping research focuses on how individuals acquire, learn, develop, think about, and store data relating to the everyday geo- graphic environment and on the actual knowledge that is acquired (Downs \& Stea, 1973). This research has the potential to be of great benefit to persons with visual impairment or blindness (Pick, 1980). The information is also useful to urban planners, mobility specialists, and navigation aid designers (Kitchin, 1994). It is hypothesized that an understanding of how persons with visual impairment or blindness understand space 'could lead to the- planning of environments that are easy to remember and that facilitate greater and more pleasurable use. This understanding could also provide knowledge about the content, form, and location of spatial information that should be made available to blind or visually impaired pedestrians. In addition, it could provide clues about how to enhance this group's wayfinding and orientation skills by supplying feedback on current knowledge and strategies of thought. Such 
feedback could provide mobility specialists with information on how to teach more effective strategies of spatial thought and could provide navigation aid designers with benchmarks for measuring the impact and effectiveness of various training strategies and mobility aids. The need for an effective and reliable assessment becomes ever more apparent with the accelerating development of new technological aids for persons who are blind or visually impaired, such as NOMAD, an audio-tactile graphics processor (Parkes, 1988); personal guidance systems (Balachandran, 1995; Golledge, Loomis, Klatzky, Flury, \& Yang 1991; Petrie, 1995), talking signs (Brabyn, 1995); and Atlas Speaks, a talking orientation tool (Fruchterman, 1995).

Researchers have used a whole range of techniques to assess the cognitive map knowledge of persons who are visually impaired or blind and those who are sighted. This article is divided into two sections. The techniques used by researchers from psychology, geography, urban planning, and cognitive science to assess various aspects of cognitive map knowledge are discussed in the first section. This discussion is divided into those tests that measure aspects of route knowledge (retracing, distance, and direction) and those that measure aspects of configurational knowledge (where places are located in relation to each other). When possible, examples are taken from studies in which the respondents are blind or visually impaired. Some of the tests that are reviewed in this article have not yet been used to assess the cognitive map knowledge of persons with visual impairment. Therefore, the authors hypothesized about their tests' potential to provide further comprehension and understanding. The second section of this article examines the validity of drawing conclusions from these tests, given that they focus on content and accuracy rather than on utility, that the methodological convergence between them is weak, and that their reliability is generally unknown. In addition, the authors explored the problems inherent in research that generally assesses small sample sizes and the respondents' knowledge of microscale, artificial environments rather than real-world macro-spaces that people interact with in their daily lives.

\section{Review of measurement techniques}

\section{ROUTE-BASED TECHNIQUES}

Route-based techniques aim to determine a respondent's knowledge of the relationship between two locations and how to travel between them. Tests to measure this type of knowledge can be divided into three categories. In the first category, respondents can be asked to retrace or infer a route. Passini, Proulx, and Rainville (1990) compared sighted, blindfolded sighted, congenitally and adventiously blind, and visually impaired respondents' ability to retrace a route from the destination to the point of origin. Klatzky et al. (1990) compared sighted and blindfolded respondents' ability to return directly to the origin from the destination after they had traversed a two-to-three-segment route. These types of techniques have utility because they study an individual's interaction with a space, whereas other techniques might only infer knowledge and possible behavior from the test results.

In the second category of tests, respondents can be asked to estimate the distance between the start and end nodes of a route or of the segments that make up that route. 
Montello (199 1) classified tests designed to measure cognitive distance estimates into the following five subgroups: 1) psychophysical ratio scaling, 2) psychophysical interval or ordinal scaling, 3) mapping, 4) reproduction, and 5) route choice. The first two of these methods use traditional psychophysical scaling techniques that differ in the level of measurement. Montello (1991) described four ratio scaling techniques, two of which are applicable to the testing of cognition of largescale distances. Magnitude estimation requires a respondent to assign a number to a distance, scaled in relation to a given value. For example, the distance between London and Paris could be assigned a scale value of 100. The respondent would then be required to estimate the distances between other locations in comparison to this value, with places closer together receiving a lower value and places further apart receiving a higher value. Allen, Siegel, and Rosinski (1978) and Cadwallader (1979) have both used this technique to obtain distance estimates. Ratio estimation requires the respondent to mark on a line the distance to a location, with the length of the line representing a given distance. Ratio estimation has been a popular technique, used by Lowery (1973); Briggs (1973, 1976); Day (1976); Phipps (1979); MacEachren (1980, 1992); Coshall (1985); Okabe, Aoki, and Hamamato (1986) and Lloyd and Heivly (1987) to collect distance estimates. These techniques all require large mental transformations and scaling.

Montello (1991) classified psychophys' ical interval or ordinal scaling techniques into four subgroups. Paired comparison requires the respondent to decide which one of a pair of distances is longer (Biel, 1982) and in a similar triad method, respondents are presented with three locations and asked to judge which of the three is furthest from the other two (Allen, 1981; Magana, Evans, \& Romney, 198 1). Ranking requires respondents to rank distance in an order along the dimension of length (Allen et al., 1978; Kosslyn Pick, \& Farriello, 1974). Rating requires respondents to assign the distance between places to a set of predetermined classes that represent relative length (Baird, Merrill, \& Tannenbaum, 1979). Partition scales require the respondent to assign distances to classes of intervals that appear to be equal in length (Cadwallader, 1979). These techniques are generally used to collect data for nonmetric multidimensional scaling wherein data is converted into a two-dimensional format (see configuration techniques). These methods of data collection might have more utility for measuring visually impaired or blind individuals' knowledge of place separation than to the magnitude or ratio estimation techniques because they require only categorization rather than more precise scaling estimates.

Mapping requires several locations to be represented simultaneously on a scale smaller than the estimated environment. It is discussed in the next section. Reproduction requires respondents to provide distance estimates on a scale of the estimated distance. This technique has -potential for use in studies of visually impaired individuals' knowledge of distances because it requires few mental transformations or scaling estimates and is on the scale that is most familiar to respondents. Route choice requires individuals to infer judgments of cognitive distance from their route choices. This technique might have little utility in the study of how visually impaired' individuals cognize distance 
because their choice of routes is often constrained to known paths.

In several studies, respondents were asked to judge Euclidean distances between locations. For example, MacKay and Zinnes (198 1) and Matthews (1981) asked children to estimate, in miles, distances between locations. Other researchers have used such familiar units as the scale of use in magnitude estimation (Briggs, 1976; Cadwallader, 1976; Saisa, SvenssonGärling, Gärling, \& Lindberg, 1986). Day (1976) had respondents mark a dash along a line that had miles marked along its length. The use of such units in studies of visually impaired individuals' knowledge is questionable, and Rieser, Lockman, and Pick (1980) found that visually impaired persons had difficulty estimating Euclidean distances between locations but had less difficulty estimating functional distance. However, Haber, Haber, Levin, and Hollyfield (1993) found that visually impaired respondents could accurately estimate Euclidean distances within smallscale spaces. Alternative units of measurement that might have more utility in the assessment of visually impaired respondents are the estimation of travel time or the measurement of functional distance in units such as paces. .

In the third category of tests, respondents could be asked to estimate the direction between the start and end nodes of a route or between various locations along a route's length. Pointing was used by a number of studies of both sighted (Kirasic, Allen, \& Siegel, 1984) and visually impaired (Bigelow, 1991; Bryne \& Salter, 1983; Dodds, Howarth, \& Carter, 1982; Herman, Cratiman \& Roth, 1983) individuals. In general, the method requires the respondents to stand, or imagine that they are standing, at a location and then to point to another location. Additionally, respondents can be asked to draw a line across a compass representing the direction to a place, when the central point represents the origin.

\section{CONFIGURATIONAL TECHNIQUES}

\section{Graphic tests}

Tests to measure configurational knowledge can be divided into four categories. Graphic test methods are all variations on sketch mapping. There are five basic sketch mapping variations.. The basic sketch mapping technique is designed to obtain from the respondent a freely drawn and solicited sketch map that has been only minimally defined by the researcher. The respondent is given a blank piece of paper and is asked to map a given environment. The normal sketch mapping technique imposes more constraints on the respondent than the basic approach. The researcher is often interested in more specific features and will word the instructions appropriately to obtain the required data. In cued sketch mapping, the respondent is given a portion of the map and asked to complete specific features. The longitudinal sketch mapping technique allows the researcher to study how the sketch map evolves. The instruction set is similar to the normal procedure, but it requires the respondent to provide the sketch map on layers of carbon or tracing paper. After certain time periods, the sheets of paper are turned over and the respondent continues to draw. Beck and Wood (1976a, 1976b) and Wood and Beck (1976) argued that teaching respondents a sketch mapping language produces maps that are not compromised by graphic ability or a lack of mapping knowledge. They developed a 
sketch mapping language called "Environmental A" for use by school children. It might be anticipated that visually impaired individuals will experience trouble with graphically based tasks because they require the drawer to select, classify, simplify, and symbolize their knowledge to cartographic conventions and to manipulate it into a representation synonymous with a bird's-eye view, which is never experienced by individuals who are blind. However, Jacobson (1992) has successfully used the normal sketch mapping procedure to collect drawings representing blind individuals' knowledge of the University of Wales Swansea campus. In that study, respondents used a raised-line drawing board to sketch the campus area prior to, and after, learning a tactile map of the area. Although the respondents' initial reaction was one of refusal, each individual, with encouragement, not only drew the campus, but was remarkably. accurate when compared to the learned tactile map. Downs and Stea (1977) also reported on a blind student who could accurately draw an outline map of the United States after learning a tactile map.

\section{Partially graphic and reconstruction tests}

Partially graphic and reconstruction test methods provide respondents with a certain amount of attendant spatial information.. Spatial cued response methodologies are essentially location testers. They differ from sketch mapping in that they require only the placing of points. This reduces the motor skill component of drawing to a minimum and provides a structured framework for respondents' responses. There are various techniques, but the basic method is that of Thomdyke and Hayes-Roth (1982), who asked respondents to place a location in relation to two points, one the starting pc of a route and the other an arbitrary lo tion. This method provides a scale and orientation for the respondent. Buttenfi (1986) altered the methodology so t instead of performing a series of triad tes a whole series of locations were placed relation to the coastline (see Figure 1). $T$. test could easily be converted for use $\mathrm{w}$ visually impaired individuals, with the i: tial spatial cue taking the form of a rais tactile surface or for use with individu: with low vision if it took the form of enhanced graphic. Because of the reducti in motor skills, the spatial cued respor test has more utility for measuring $t$ knowledge of blind individuals than $\mathrm{dc}$ the sketch mapping technique. The $d$ a from spatial cued response tests can quantitatively analyzed using bidime sional regression (Kitchin, 1993), which a two-dimensional equivalent of ordina least squares linear regression that allor two sets of coordinates to be compar (Tobler, 1965). In this case, the two sets coordinates being compared are the cog- $\mathrm{X}$ tive and real-world locations. This regre sion technique is sensitive to rotatior translations, and changes of scale and cz culates how large they are (Tobler, $197 t$ In addition, a series of calculations can 1 used to measure the amount and type of di tortion contained within respondents' repr sentations (Waterman \& Gordan, 1984).

The cloze procedure test is a spatial cor pletion test. Traditionally, the responde fills in the blank space. An aspatial examp would be, "A dog barks but a cow Robinson (1974) and Boyle and Robinss (1978) have extended this exercise sp tially. A base map is covered with a gri and the information contained in some , the squares is deleted. Respondents are the 


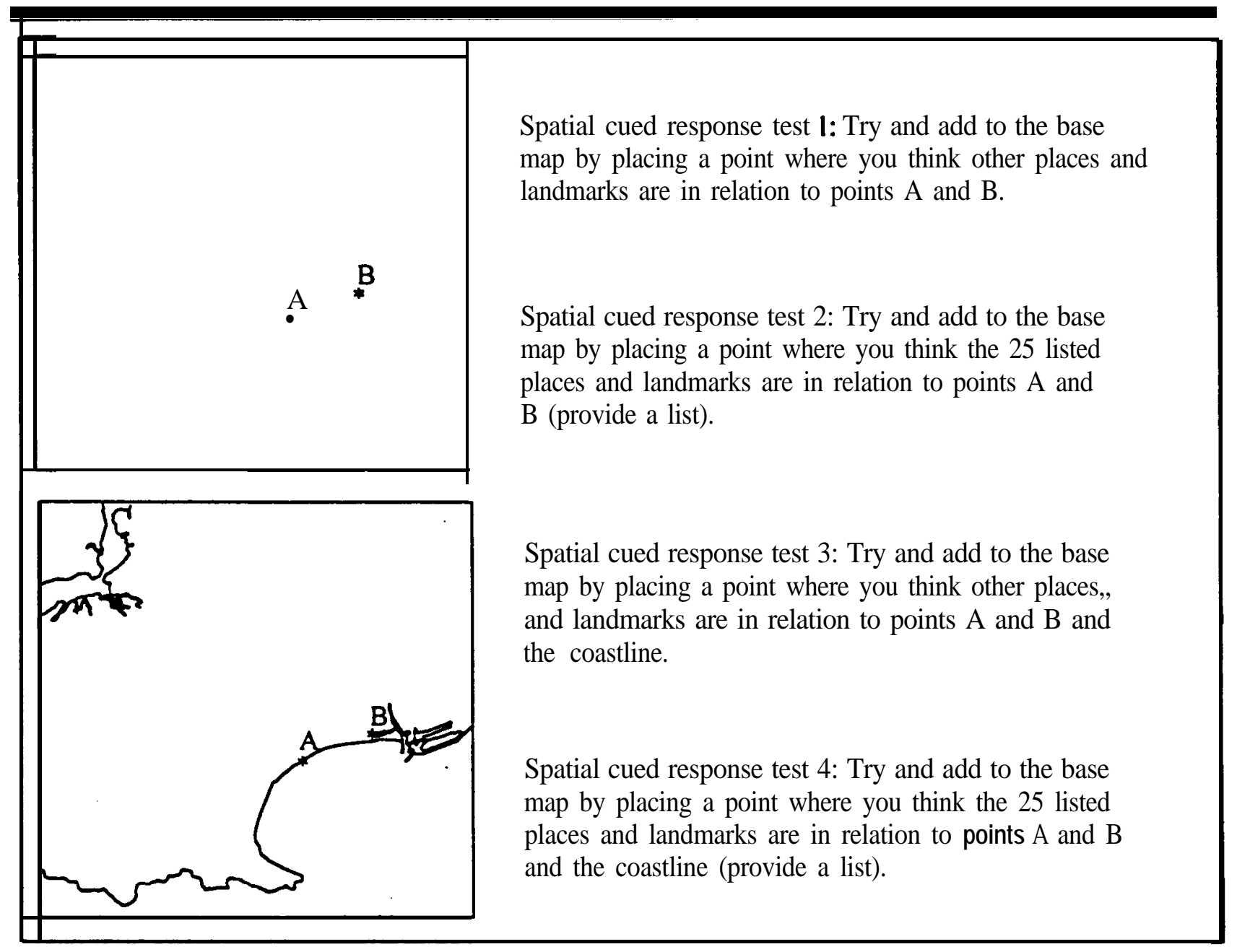

Figure 1. Example of a spatial cued response test.

asked to identify particular elements in these blank squares with the aid of the contextual information retained in the remaining open squares. The results can be quantitatively analyzed by constructing an accuracy score that represents how well an individual did in assigning places to the boxes. This score is simply the percentage of boxes with places correctly assigned to them. This test could easily be converted for use with visually impaired respondents by giving them a tactile map with blank spaces and asking them either to match given places to spaces (cued) or to decide what places might be in each square (uncued) (see Figure 2). Burroughs and Sadalla (1979) used a similar technique called sentence frames. Respondents were required to complete a set of frames that took the typical format of: " is close to " and “ is essentially. next to " These sentence frames. might have particular utility because they involve no graphic externalization.

Reconstruction tasks allow the respondent to build a model of an environment. They have been successfully used to study visually impaired individuals' knowledge of an area. For example, Casey (1978) asked 10 congenitally blind students, aged 17 to 20 , and 10 partially sighted students, aged 16 to 21, to construct a map of their school using a modeling kit consisting of 22 


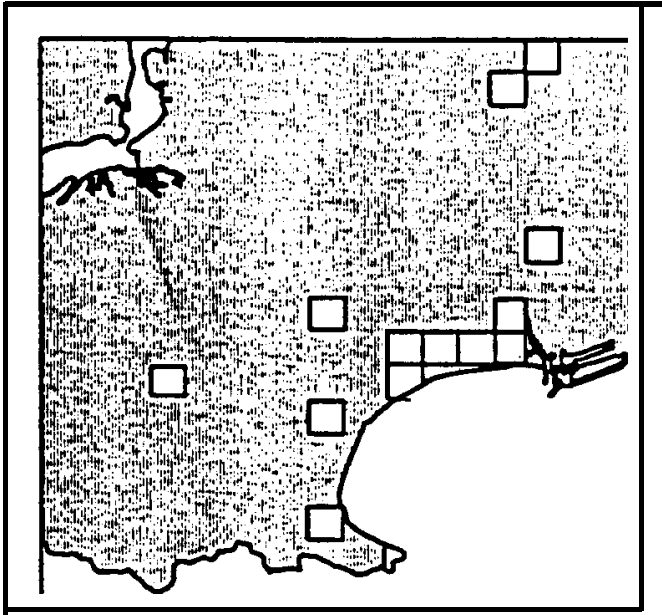

Cloze procedure test 1: Write in the blanked out boxes the number of a place or landmark that has been removed. Write the place that number represents in the spaces below.

Cloze procedure test 2: Write in the blank boxes the number of the place or landmark from the fifteen listed below that has been removed (provide a list).

Figure 2. Examples of cloze procedure tests.

wooden building blocks labeled in print and braille and adhesive strips that represented roadways and paths. Passini and Proulx (1988) used a similar modeling kit consisting of wooden blocks $2 \mathrm{~cm}$ in length and miniature stairs and circles that indicated entrances and exits. Each block had a magnetic strip so that it could be attached to a metal board. These models can be assessed both in terms of their content and their accuracy.

\section{Uni-to-multidimensional tests}

Uni-to-multidimensional techniques, such as multidimensional scaling and projective convergence, use route knowledge data to explore the latent, or inferred, structure of configurational knowledge. They do this by constructing a two-dimensional space from the one-dimensional data that is provided, using a series of algorithms.. Multidimensional Scaling (MDS) is a technique that is designed to construct a map showing the relationship between a number of objects, given only a matrix of distances between them (Aitken, Cutter, Foote, \& Sell, 1989). These distances can be either all metric or all ordinal. The purpose of this technique is to discover the pattern or struc- ture in a collection of empirical data and tc represent that data visually (Golledge. 1977). The algorithm minimizes the difference, or stress,. between the patterns of proximities in the matrix and the space created (Montello, 1991). Haber et al. (1993; successfully used the MDS method to compare blind and sighted individuals' Euclidean distance estimates and Lockman. Rieser, and Pick (1981) have implemented a nonmetric equivalent. In the Lockman et al. (1981) study, respondents were presented with the names of three locations and asked to determine which two places were furthest apart and which two were closest together. Respondents completed a series of these questions and the results were nonmetrically multidimensionally scaled to produce a two-dimensional map.

Whereas the MDS method constructs a configuration from a matrix of distances. the projective convergence, or resection. method uses direction estimates to work ou the coordinates of locations. Typically. respondents estimate the distance and direction to unseen places from three 01 more locations. The resulting vectors car be drawn and where the lines end, a triangle of error can be drawn whose mean center is 
taken as the cognitive location of a place (see Figure 3b). Hardwick,, McIntyre, and Pick (1976) originally developed the method in a study wherein respondents first familiarized themselves with four locations within a library. Screens were then erected and respondents were asked to estimate the direction by pointing a sighting tube in the direction of the four unseen locations. By calculating where the lines intersected, the triangle of error could be found and a cognitive location could be calculated (see Figure 3a). Kirasic, Siegel, and Allen (198 1) first used the distance/direction method (see Figure 3b) in a study of 48 students and their memory of locations on a university campus, using a direct magnitude method for eliciting distances. In a second experiment (Kirasic et al., 1984), they devised a method wherein distance and direction were recorded simultaneously, with respondents drawing a line that represented both.

\section{Recognition tests}

Recognition methods collect configurational knowledge data by providing the respondents with a representation of an environment and asking them to correctly identify features and configurations, as in map/configuration recognition or aerial photograph recognition. For example, Evans, Fellows, Zom, and Doty (1980) asked respondents to identify four out of eight floor plans that they had just walked through. Evans and Pezdek (1980) gave respondents a set of triad configurations, only half of which were correct. These configurations were either nonrotated or rotated by 60,120 , or 180 degrees. Respondents were shown the triads one at a time and asked to say which configuration had the places correctly located relative to each other, despite the rotation, and reaction times were noted. A similar method was used by Kitchin (1995) (see Figure 4). Recognition tests are likely to have great utility for measuring the configurational knowledge of individuals who are visually impaired or blind because the configurations can be easily displayed tactilely and respondents only have to determine which configuration is correct. However, the authors are unaware of any study that has utilized this method to asses the configurational knowledge of visually impaired individuals.

\section{Issues of validity}

There are a number of important issues relating to the use of these techniques as valid indicators of the cognitive map knowledge of individuals who are visually impaired or blind. At a basic level, the authors question whether these tests are a suitable way to measure a visually impaired individual's knowledge of, or ability to learn, an area. All of these tests measure an individual's knowledge in terms of accuracy, mainly in relation to another representation of an environment (Euclidean distances, a map, or a building plan), rather than utility. For any individual, the utility of their knowledge - whether it can get them from point $A$ to point $B-$ is far more relevant than a correspondence between their knowledge and a geometrical abstraction. The utility of someone's knowledge is best assessed through tasks that demonstrate it in action, such as wayfiiding in a complex environment. However, assessing utility in real-world environments is difficult because of complicating factors. For example, when individuals are wayfinding in a complex environment, are they using 


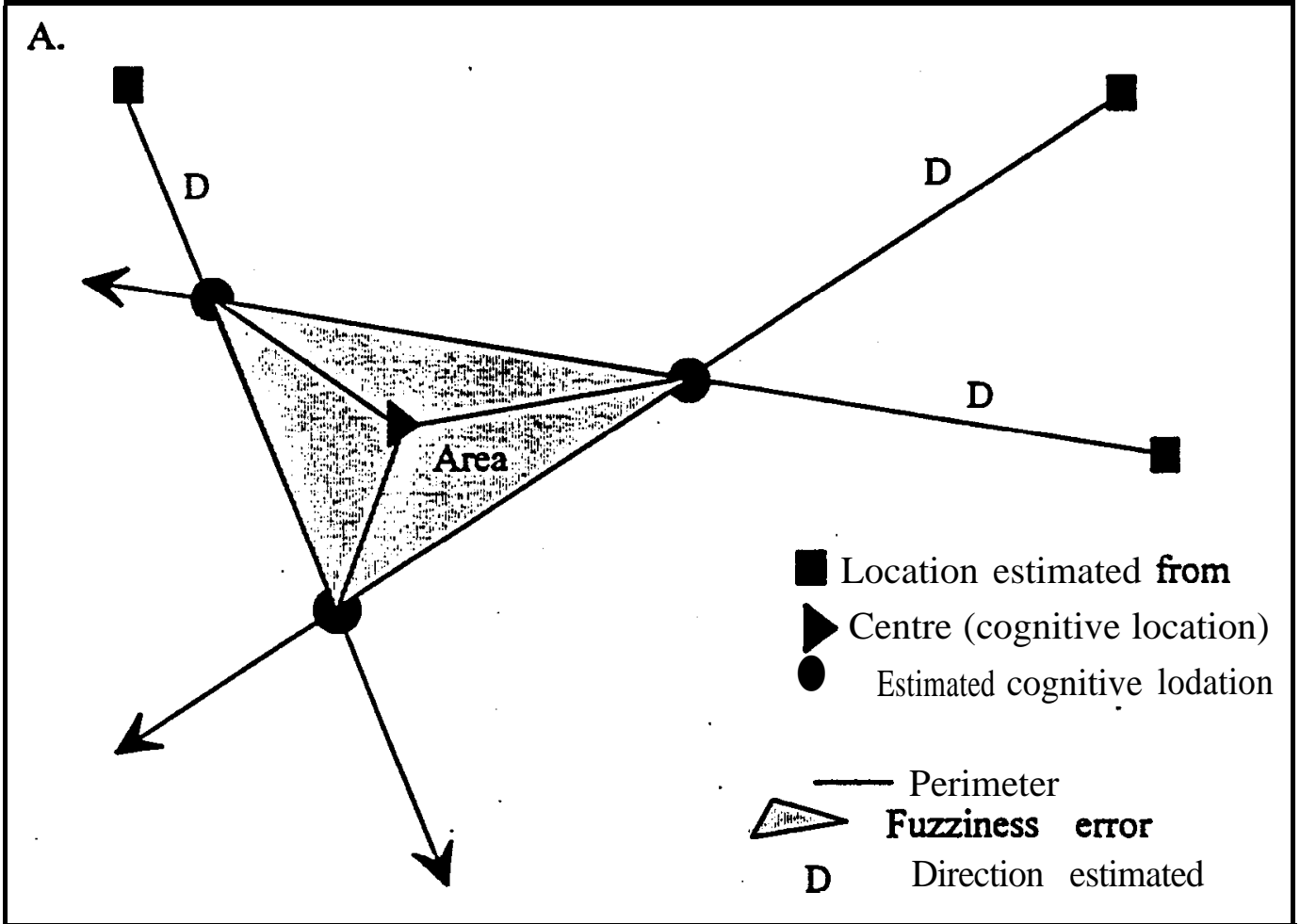

B.

Location estimated from

Centre (cognitive location)

Estimated cognitive location

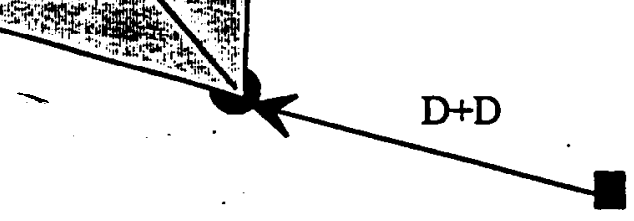

Perimeter

$\longrightarrow$ Fuzziness error

$\mathrm{D}+\mathrm{D}$ Distance and direction estimatdd

Figure 3. Projective convergence technique for converting unidimensional estimates into coordinates. Sources: A. Hardwick et al. (1976), B. Kirasic et al. (1981). 


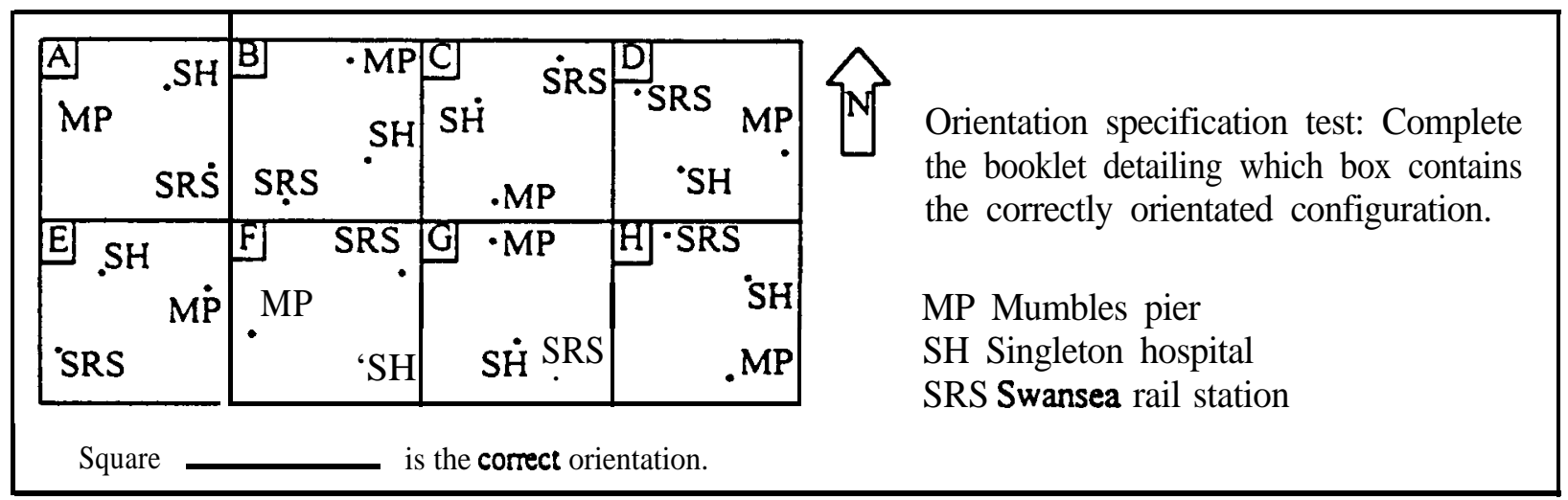

Figure 4. Example of a recognition test.

their cognitive map knowledge to guide their actions, cues in the environment to guide their actions, or 'both? This is an important question when trying to determine if visually impaired individuals are capable of developing spatial representations of environments.

In their defense, these techniques do provide the opportunity to discover knowledge content and assess how accurate this knowledge is, with the inference that the greater the accuracy of the knowledge, the more utility it has. Currently, despite a number of studies, knowledge of how persons with visual impairment or blindness learn, understand, and think about geographic space is limited (Passini \& Proulx, 1988), and the answers to many questions about that knowledge are incomplete. For example, can a person with. visual impairment or blindness achieve an adequate spa\&l representation of a complex, real-world environment? To what extent does lack of vision impoverish an individual's cognitive map 'knowledge? Do persons with visual impairment or blindness have the same skills, abilities, and knowledge structures as sighted persons do? Do they use spatial information to solve problems or respond to life experience in the same way as sighted persons do? How do persons with visual impairment or blindness learn a new environment and update existing knowledge with new information? What is the role of spatial perception in the formation of cognitive map knowledge and active spatial behavior by blind or visually impaired persons? What exploration strategies are used by wayfinders who lack sight? (Blades, Golledge, \& Kitchin, in press).

These tests do provide the opportunity to explore and answer these questions. Furthermore, they have led to the formation of three theories related to the visually impaired individual's ability to understand spatial relationships: 1) the deficiency theory, which states that congenitally blind individuals are unable to develop a general spatial understanding because they have never experienced the perceptual processes (vision) necessary to comprehend complex spatial arrangements (Golledge, 1993); 2) the inefficiency theory, which states that persons with visual impairment can understand and mentally manipulate spatial concepts, but because information is based on auditory and haptic cues, this knowledge and comprehension is inferior to that based on vision (Spencer, Blades, \& Morsley, 1989); and 3) the difference theory, which states that visually impaired individuals possess the same abilities to process and, 
understand spatial concepts and that any differences, either in quantitative or qualitative terms, can be explained by intervening variables, such as access to information, experience, or stress (Passini \& Proulx, 1988). These theories now need to be extensively examined using the tests outlined.

The tests do, however, have a number of problems and unknown qualities. First, many studies have shown that these tests have weak methodological convergence. In other words, they produce different results for the same individual even when the tests have similar characteristics (such as two partially graphic tests). For example, Howard, Chaser and Rothman (1973), Cadwallader (1979), and Montello (199 1) found that tests designed to measure distance cognition produced varying results. Similarly, MacKay (1976), Magana et al. (1981), Bryant (1984), and Matthews (1984) found that tests designed to measure aspects of configurational knowledge produced contrasting findings. Although these studies reported that differences existed, the specific reasons for any differences were not discovered.

Recently, Kitchin (1995) studied the results from 13 tests designed to measure aspects of configurational knowledge in an attempt to ascertain why different tests produced varying results. Six groups of individuals each completed a set of four different tests. Each of the four tests were drawn from a different category of test types (graphic, partially graphic, uni-tomultidimensional, and recognition). Tests - were found to introduce varying amounts of methodological bias into an individual's results. These biases were found to be caused by differences both in the amount of spatial information provided to the respon- dent and the amount of inforrnatio requested by the respondent. Differer combinations of these two factors cause varying results and their relationship wa found to be quite complex. For exampls when provided with little spatial informs tion and requested to locate a set number $\mathrm{c}$ designated places, large residuals wer introduced into the analysis because th respondents did not know the locations $\mathrm{c}$ certain places. When provided with a set $\mathrm{c}$ spatial locations and asked to identify whe place was at which location, residual errc was introduced because the respondents di not know the places at certain location: Additionally, some tests were discovered $t$ be too abstract for respondents, requirin: them to use skills that were not well devel oped. For example, respondents had diffi culty estimating absolute (Euclidean) dis tances between places but found it easier $t$ estimate relative distances. As a result, indi viduals varied in how they did in compar ison to their peers and an abstraction of th real world, such as a map. Two main con clusions can be drawn from this study: 1 no one test can produce superior result: because each test introduces some biase: into the analysis; and 2) multiple, mutually supportive tests should be used to assess ar individual's configurational knowledge sc that a complete picture can be formed.

A good example of a study that adopt: such a multiple, mutually supportive approach is Passini et al. (1990). In thi: study, respondents learned a complex mazt and then took eight different tests to allor an assessment of their acquired knowledge These tests included inverting a route, combining routes, learning models and ther executing behavior, making shortcuts anc mental rotations, and building models of layouts. By using eight tests, Passini et al 
(1990) acquired a clear picture of respondents' cognitive map knowledge that confirmed two conclusions drawn from an earlier study: 1) blind individuals do understand the geometric characteristics of a setting to an extent that is comparable to sighted individuals' understanding (Passini \& Proulx, 1988) and 2) any differences are due to distant cues and visual reference points that are not accessible to blind individuals.

Additionally, with regard to weak methodological convergence, most studies to date have assumed that the methods used to elicit knowledge would be reliable. A reliable test is a test that consistently elicits the same response from an individual, despite nuances in the individual's knowledge or character. Blades (1990), in a unique study, tested the reliability of sketch mapping data by testing respondents' knowledge on two occasions one week apart. He concluded that sketch mapping is a consistent measure over a short period of time. However, Walmsley, Saarinen, and McCabe (1990) argued that because sketch mapping is a reactive technique and the drawing of an area affects subsequent drawings of that same area, it is difficult to assess replicability. Siegel and Cousins (1985) further argued that if differences do occur,' it might not be surprising because participants' responses are re-representations that are two levels removed from the actual environments (environments $\rightarrow$ cognitive map knowledge of environment $\rightarrow$ test result). Consistent data, and hence the same conclusions, need to be produced by these tests in order to have confidence in their utility.

Currently, many studies of visually impaired persons' cognitive map knowledge have very small sample sizes. This is problematic because as sample size decreases, it becomes increasingly more difficult to draw generalizations concerning the knowledge and ability of other visually impaired persons. For example, Bigelow (1991) only had two blind respondents, two visually impaired respondents, and eight sighted respondents. How valid is it to compare groups when the sample sizes are so small, let alone to draw conclusions about spatial development? Haber et al. (1993) used only seven respondents in two groups (blind and sighted, familiar) and six in another (sighted, unfamiliar); Bryne and Salter (1983) used only eight blind and eight - sighted respondents; Rieser, Guth, and Hill (1986) used only six blind respondents (familiar) and six blind respondents (unfamiliar) in one study and six earlyblind, six late-blind, and six sighted respondents in a second study; Hollins and Kelley (1988) used only six blind respondents and six sighted respondents in their four experiments. It is acknowledged that recruiting respondents remains a difficult task, but every effort should be made to achieve workable sample sizes from which more valid conclusions can be drawn.

There is another issue that relates to the scale of the environments used by researchers as test areas. Currently, most studies of visually impaired persons' spatial and wayfinding abilities concern microscale environments. For example, Hollins and Kelly (1988) and Juurmaa and Lehtinen-Railo (1994) studied how visually impaired persons learn limited layouts of objects, and Passini et al. (1990) studied these individuals' learning in small, specially constructed spaces ' suitable for people to walk through. A few researchers have tested blind persons' wayfinding performance in real environments, but most 
have only asked individuals to walk a short route with one or two choice points (Dodds et al., 1982; Herman et al., 1983; Leonard \& Newman, 1967). Only rarely has blind persons' cognitive map knowledge been tested in complex environments. Passini and Proulx (1988) examined blind adults' ability to find their way through an unfamiliar university building. Small spaces, short routes, and corridors of buildings are only a subset of the environments experienced by blind persons, and it is difficult to extrapolate from performance in such spaces to performance in everyday environments. Wayfinding in large-scale real-world spaces is different from wayfinding in limited areas. On the one hand, there are more sources of information (such as sounds, smells, and wind direction) for routefinding in real-world spaces; on the other hand, there are distractions and complications resulting from the presence of obstacles and other people and the possibility of unexpected changes and diversions along the route (Blades et al., in press). There is a real need to assess cognitive mapping knowledge and ability in environments that persons who are blind or visually impaired actually experience on a daily basis.

\section{Conclusion}

Valid measurement of cognitive map knowledge has many implications relating to urban planning, education, and navigation aids. In particular, at a time when many navigation and mobility aids are being developed, it is vital that their utility in improving wayfmding and orientation can be assessed.

Although a diverse number of methodologies for assessing the cognitive map knowledge of persons who are blind or visually impaired have been produced, those techniques and their results need to be used cautiously. All of the tests introduce some form of methodological bias because they provide the respondent with different amounts of given spatial information and vary in the amount of information that respondents request. These variations affect how well respondents perform on a test, both in comparison to their peers and to abstractions of the real world (maps). The reliability of these tests is also unknown, although parallels to other psychological tests suggest that they should be consistent in nature (Anatasti, 1990; Cronbach, 1990). To i\&prove the utility and validity of these tests, researchers should use multiple. mutually supportive tests in order to builc up a complete picture of a respondent' 5 knowledge. Each of these technique: should be rigorously tested for reliability prior to a study. It is essential that larger sample sizes, with a minimum of $1 \mathrm{C}$ respondents in each group, be used to try and establish a basis for generalizations Furthermore, research should start to asses: the knowledge and abilities within comples real-world environments that everyont inhabits, rather than inferring that result: from the laboratory will exist in natural set tings. These tests could provide an opportu nity to study a wide range of questions con cerning how persons with visual impair ment or blindness understand and compre hend the world around them. They als could reveal important implications con ceming planning and education. Ever. effort should be made to successfull: implement them in order to increase th validity of research findings. 


\section{References}

Aitken, S.C., Cutter, S.L., Foote, K.E., \& Sell, J.L. (1989). Environmental perception and behavioral geography. In Wilmott, C. \& Gaille, G. (Eds.), Geography in America (pp. 2 18-238). London: Merrill.

Allen, G. (198 1). A developmental perspective on the effects of "subdividing" macrospatial experience. Journal of Experimental Psychology: Human Learning and Memory, 7, 120-132.

Allen, G., Siegel, A.W., \& Rosinski, R.R. (1978). The role of perceptual context in structuring spatial knowledge. Journal of Experimental Psychology: Human Learning and Memory, 4, 617-630.

Anastasi, A. (1990). Psychological testing (6th ed.). New. York: Macmillan.

Baird, J.C., Merrill, A., \& Tannenbaum, J. (1979). Studies of cognitive representations of spatial relations II: A familiar environment. Journal of Experimental Psychology: General, 108, 92-98.

Balachandran, W. (1995, February). Satellite navigation system for blind pedestrians. Paper presented at the Conference on Orientation and Navigation Systems for Blind Persons, Hatfield, United Kingdom.

Beck, R.J. \& Wood, D. (1976a). Cognitive transformations from urban geographic fields to mental maps. Environment and Behavior, 8, 199-238.

Beck, R.J. \& Wood, D. (1976b). Comparative developmental analysis of individual and aggregated cognitive maps of London. In G.T. Moore \& R.G. Golledge (Eds.), Environmental Knowing (pp. 173-184). Stroudsberg, PA: Dowden, Hutchinson and Ross.

Biel, A. (1982). Children's spatial representation of their neighborhood: A step towards a general spatial competence. Journal of Environmental Psychology, 2, 193-200.

Bigelow, A. (199 1). Spatial mapping of familiar locations in blind children. Jourmal of Visual Impairment \& Blindness, 85, 113-117.

Blades, M. (1990). The reliability of data collected from sketch maps. Journal of Environmental Psychology, 10, 327-339.

Blades, M., Golledge, R.G., \& Kitchin, R.M. (in press). Understanding the geographic world without the use of vision. Progress in Human Geography.
Boyle, J.M. \& Robinson, M.E., (1978). Cognitive mapping and understanding. In D.T. Herbert \& R.J. Johnston (Eds.), Geography in the urban environment (Vol. 2, pp. 59-82). London: Wiley.

Brabyn, J. (1995, February). Orientation and navigation systems for the blind: An overview of different approaches. Paper presented at the Conference on Orientation and Navigation Systems for Blind Persons, Hatfield, United Kingdom.

Briggs, R. (1973). Urban distance cognition. In R.M. Downs \& D. Stea (Eds.), Image and Environment (pp. 361-388). Chicago: Aldine. Briggs, R. (1976). Methodologies for the measurement of cognitive distance. In G.T. Moore \& R.G. Golledge '(Eds.), Environmental knowing (pp.' 325-334). Stroudsberg, PA: Dowden, Hutchinson and R o s s .

Bryant, K.J. (1984). Methodological convergence as an issue within environmental cognition research. Journal of Environmental Psychology, 4, 43-60.

Burroughs, W. \& Sadalla, E. (1979). Asymmetries in distance cognition. Geographical Analysis, 11, 414-42 1 .

Buttenfield, B.P. (1986). Comparing distortion on sketch maps and MDS configurations. Professional Geographer, 38, 238-246.

Byrne, R.W. \& Salter, E. (1983). Distances and directions in cognitive maps of the blind. Canadian Journal of Psychology, 37, 293-299.

Cadwallader, M.T. (1976). Cognitive distance in intraurban space. In G.T. Moore \& R.G. Golledge (Eds.), Environmental Knowing (pp. 316324). Stroudsberg, PA: Downden, Hutchinson and Ross.

Cadwallader, M.T. (1979). Problems in cognitive distance and their implications to cognitive mapping. Environment and Behavior; 11, 559-576.

Casey, S.M. (1978). Cognitive mapping by the blind. Journal of Visual Impairment \& Blindness, 72, 297-301.

Clark-Carter, D.D., Heyes, A.D., \& Howarth, C.I. (1986). The efficiency and walking speed of visually impaired pedestrians. Ergono mi cs, 29, 779-789.

Coshall, J.T. (1985). Urban consumers' cognitions of distance. Geografiska Annaler, 67B, 107-1 19. 
Cronbach, L.J. (1990). Essentials of psychological testing. New York: Harper Collins.

Day, R.A. (1976). Urban distance cognition: Review and contribution. Australian Geographer; 13, 193-200.

Dodds, A.G., Howarth, C.I., \& Carter, D.C. (1982). The mental maps of the blind. Journal of Visual Impairment \& Blindness, 76, $S-12$.

Downs, R.M. \& Stea, D. (1973). Cognitive maps and spatial behavior: Process and products. In R.M. Downs \& D. Stea (Eds.), Image and Environment (pp. 8-26). Chicago: Aldine.

Downs, R. \& Stea, D. (1977). Maps in minds: Reflections on cognitive mapping. New York: Harper and Row.

Evens, G.W., Fellows, J., Zom, M., \& Doty, K. (1980). Cognitive mapping and architecture. Journal of Applied Psychology, 65, 474-478.

Evans, G.W. \& Pezdek K. (1980). Cognitive mapping: Knowledge of real-world distance and location information. Journal of Experimental Psychology: Human Learning and Memory, 6, 13-24.

Fruchterman, J. (1995, February). Arkenstone's orientation tools: Atlas speaks and strider. Paper presented at the Conference on Orientation and Navigation Systems for Blind Persons, Hatfield, UK.

Golledge, R.G. (1977). Environmental cues, cognitive mapping and spatial behavior. In Burke, D. et al. (Eds.), Behavior-Environment research methods (pp. 35-46). Madison, WS: Institute for Environmental Studies, University of Wisconsin.

Golledge, R.G. (1993). Geography and the disabled: A survey with special reference to vision impaired and blind populations. Transactions of the Institute of British Geographers, 18, 63-85.

Golledge, R.G., Loomis, J.M., Klatzky, R.L., Flury, A., \& Yang, X.L. (1991). Designing a personal guidance system to aid navigation without sight: Progress on the GIS component. International Journal of Geographical Information Systems, 5, 373-395.

Haber, R.N., Haber, L.R., Levin, C.A., \& Hollyfield, R. (1993). Properties of spatial representations: Data from sighted and blind subjects. Perception and Psychophysics, 54, 1-13.

Hardwick, D.A., McIntyre, C.W., \& Pick, H.L. (1976). The content and manipulation of cog- nitive maps in children and adults. Monographs of the Society for Research in Child Development, 41, l-55.

Herman, J.F., Chatman, S.P., \& Roth, S.F. (1983). Cognitive mapping in blind people: Acquisition of spatial relationships in a large scale environment. Journal of Visual Impairment \& Blindness, 77, 161-166.

Hill, E.W., Rieser, J.J., Hill, M.-M., Hill, M., Halpin, J., \& Halpin, R. (1993). How persons with visual impairments explore novel spaces: Strategies of good and poor performers. Journal of Visual Impairment \& Blindness, 87, 295-30 1.

Hollins, M. \& Kelly, E.K. (1988). Spatial updating in blind and sighted people. Perception and Psychophysics, 43, 380-388. Howard, R.B., Chase, S.D., and Rothman, M. (1973). An analysis of four measures of cognitive maps. In .W.F.E. Preisner (Ed.), Environmental Design Research, (Vol. 4, pp. 254-264). Stroudsberg, PA: Dowden, Hutchinson and Ross.

Humpbreys, J.S. (1990). Place learning and spatial cognition: A longitudinal study of urban newcomers. Tijdschrift Voor Econmische en Sociale Geografie, 81, 364-380.

Jacobson, R.D. (1992). Spatial cognition through tactile mapping. Swansea G e o grapher ; 29, 79-88.

Juurmaa, J. \& Lehtinen-Railo, S. (1994). Visual experience and' access to spatial knowledge. Journal of visual Impairment \& Blindness, 88, 157-170.

Kirasic, K.C., Allen, G., and Siegel, A. (1984). Expression of configurational knowledge of large scale environments. Environment and Behavior, 16, 687-7 12.

Kirasic, K.C., Siegel, A.W., \&Allen, G. (1981). The development of basic processes in cognitive mapping: Recognition in context memory. Child Development, 51, 302-305.

Kitchin, R.M. (1993). Using bidimensional regression to analyze cognitive maps Swansea Geographer, 30, 33-50.

Kitchin, R.M. (1994). Cognitive maps: Wha: are they and why study them? Journal $\boldsymbol{o}_{j}$ Environmental Psychology, 14, 1-19.

Kitchin, R.M. (1995). Issues of validity anc integrity in cognitive mapping research. Investigating configurational knowledge Unpublished doctoral dissertation, University of Wales, Swansea. 
Klatzky, R.L., Loomis, J.M., Golledge, R.G., Cicinelli, J., Doherty, S., \& Pellegrino, J. (1990). Acquisition of route and survey knowledge in the absence of vision. Journal of Motor Behavior, 22, 19-43.

Kosslyn, S.M., Pick, H.L., \& Farriello, C.P. (1974). Cognitive maps in children and men. Child Development, 45, 707-716.

Leonard J.A. \& Newman, R.C. (1967, September). Spatial orientation in the blind. Nature, 215.

Lloyd, R. \& Heivly, C. (1987). Systematic distortions in urban cognitive maps. Annals of the Association of American Geographers, 77, 191-207.

Lockman, J.J., Rieser, JJ., \& Pick, H.L. (1981). Assessing blind travelers' knowledge of spatial layout. Journal of Visual Impairment \& Blindness, 75, 321-326.

Lowery, R.A. (1973). A method for analyzing distance concepts of urban residents. In R.M.

Downs \& D. Stea (Eds.), Image and Environment (pp. 338-360). Chicago: Aldine.

MacEachren, A.M. (1980). Travel time as the basis of cognitive distance. Professional Geographer, 38, 30-36.

MacEachren, A.M. (1992). Learning spatial information from maps: Can orientationspecificity be overcome? Professional Geographer, 44, 43 l-443.

MacKay, D.B. (1976). The effect of spatial stimuli on the estimation of cognitive maps. Geographical Analysis, 8, 439-451.

MacKay, D.B . \& Zinnes, J . L . (1981). Probabilistic scaling of spatial distance judgments. Geographical Analysis, 13, 2 l-37.

Magana, J.R., Evans, G. W., \& Romney, A.K. (1981). Scaling techniques in the analysis of environmental cognition data. Professional Geographer 33, 294-30 1.

Matthews, M.H. (1981). Children's perception of urban distance. Area, 14, 333-343.

Matthews, M.H. (1984). Cognitive maps: A comparison of graphic and iconic techniques. Area, 16,334.

Montello, D.R. (1991). The measurement of cognitive distance: Methods and construct validity. Journal of Environmental Psychology, 11, 101-122.

Okabe, A., Aoki, K., \& Hamamato, W. (1986). Distance and direction judgement in largescale natural environment: Effects of a slope and winding trail. Environment and Behavior, $18,755-772$.
Parkes, D. (1988). NOMAD-An audio-tactile tool for the acquisition, use, and management of spatially distributed information by partially sighted and blind people. In A. Dodds \& A. Tatham (Eds.), Proceedings of the Second International Conference on Maps and Graphics for the Visually Disabled, (pp. 24-29). London: King's College.

Passini, R. \& Proulx, G. (1988). Wayfinding without vision: An experiment with congenitally blind people. Environment and Behavior; 20, 227-252.

Passini, R., Proulx, G., \& Rainville, C. ( 1990). The spatio-cognitive abilities of the visually impaired population. Environment and Behavior, 22, 91-118.

Pearce, P.L. (1981). A study of travellers perceptions of a piece of countryside. Joumal of Environmental Psychology, 1, 141-155.

Petrie, H. (1995, February). User requirements for a GPS-based travel aid for blind people. Paper presented at the Conference on Orientation and Navigation Systems for Blind Persons, Hatfield, United Kingdom .

Phipps, A.G. (1979). Scaling problems in the cognition of urban distances. Transactions of the Institute of British Geographers, 4, 94-102.

pick, H.L. (1980). Perception, locomotion and orientation. In R.L. Welsch and B.B. Blasch (Eds.), Foundations of orientation and mobility (pp. 67-89). New York: American Foundation for the Blind.

Rieser, JJ., Guth, D.A., \& Hill, E.W. (1986). Sensitivity to perspective structure while walking without vision. Perception, 15 , 173-188.

Rieser, JJ., Lockman, J.L., \& Pick, H.L. (1980). The role of visual experience in knowledge of a spatial layout. Perception and Psychophysics, 28, 185-190.

Robinson, M.E. (1974). Cloze procedure and spatial comprehension test. Area, 9, 137-142.

Saarinen, T.F., MacCabe, C.L., \& Morehouse, B. (1988). Sketch maps of the world as surrogates for world geographic knowledge (Discussion paper 83-3). Tucson: University of Arizona, Department of Geography and Regional Development.

Saisa, J., Svensson-Gärling, A., Gärling, T., \& Lindberg, E. (1986). Intraurban cognitive distance: The relationship between judgements of straight line distances, travel distances, and 
travel times. Geographical Analysis, 18, 167-174.

Siegel, A.W. \& Cousins, J.H. (1985). The symbolizing and symbolized child in the enterprise of cognitive mapping. In Cohen, $\mathrm{R}$. (Ed.), The development of spatial cognition. Hillsdale, NJ: Lawerence Erlbaum.

Spencer, C., Blades, M., \& Morsley, K. (1989). The child in the physical environment. Chichester, England: Wiley.

Thomdyke, P.W., \& Hayes-Roth, B. (1982). Differences in spatial knowledge acquired from maps and navigation. Cognitive Psychology, 14, 560-589.

Tobler, W.R. (1965). Computation of the conespondence of geographic patterns. Papers and Proceedings of the Regional Science Association, 15, 131-139.

Tobler, W.R. (1976). The geometry of mental maps. In R.G. Golledge \& G. Rushton (Eds.), Spatial choice and spatial behavior (pp. 69-82). Columbus, OH: Ohio State University Press.
Walmsley, D.J., Saarinen, T.F., \& MacCabe, C.L. (1990). Down under or center stage? The world images of Australian students. Australian Geographer; 21, 164-173.

Waterman, S. \& Gordon, D. (1984). A quantitative-comparative approach to analysis of distortion in mental maps. Professional Geographer. 36, 326-337.

Wood, D. \& Beck, R. (1976). Talking with environmental A: An experimental mapping language. In G.T. Moore \& R.G. Golledge (Eds.), Environmental Knowing (pp. 35 1-361). Stroudsberg, PA: Dowden, Hutchinson and Ross.

Robert M. Kitchin, Ph.D., lecturer in human geography, School of Geosciences, Queen's University of Belfast, B17 INN, Northern Ireland, United King\&m: E-mail: <R.Kitchin@qub.ac.uk>.R. Dan Jacobson, B.Sc., research assistant, School of Geosciences, Queen's University of Belfast, BT7 INN; E-mail: <D.Jacobson@qub.ac.uk>. 